\title{
Analysis of the Caloric and Macronutrient Content of Meal Options Offered to Children at Popular Restaurant Chains
}

\author{
Andrea L. Deierlein ${ }^{*}$, Kelley Coffman and Luz Claudio
}

One Gustave L. Levy Place Box 1057, New York, NY 10029, USA

\begin{abstract}
Background: Previous research suggests that consumption of foods from restaurants is associated with poor dietary quality and adverse health outcomes. There are few studies that examine the nutrient content of children's meal options offered at both sit-down and fast-food chain restaurants. The main objective was to describe the average energy and nutrient profiles of meal options on children's menus at chain restaurants in the United States (US) and compare them to the Dietary Guidelines for Americans.

Methods: The sample consisted of 13 sit-down and 16 fast-food restaurants ranked within the top 50 US restaurant chains in 2009 (meal nutrient content was accessed in 2010). There were 421 and 275 meal options listed on children's menus from sit-down and fast-food restaurants, respectively. Descriptive statistics are presented for calories, fat, saturated fat, protein, carbohydrates, fiber, and sodium.

Results: In general, nutrient contents of children's meal options at sit-down and fast-food restaurants were similar. Meal options accounted for large percentages of the recommended daily intakes of calories, fat, saturated fat, and sodium and small percentages of the recommended daily intakes of fiber, carbohydrate, and protein for children. More than half of children's meals at these restaurants exceeded recommendations for fat and saturated fat.

Conclusions: Children's meal options at sit-down and fast-food restaurant chains that complied with the US Dietary Guidelines were limited. The majority of the meal options had fat, saturated fat and sodium contents that exceed recommendations, while providing low amounts of fiber.
\end{abstract}

Keywords: Children, restaurant, nutrition, chain, meal.

\section{INTRODUCTION}

Foods prepared away from home account for approximately one quarter of daily meals and snacks and one third of total caloric intakes for individuals ages 2 years and older [1]. Consumption of foods from restaurants is associated with less healthy dietary quality in children [2]. Among children ages 4-19 years, approximately $23-43 \%$ report eating fast-food on a typical day, resulting in a greater average daily caloric intake of 187 calories compared to non-consumers [3]. In adolescents, fast-food consumption is associated with high calorie and fat intakes [4] and increased weight and waist circumference, as well as adverse metabolic outcomes $[5,6]$.

Despite the large focus in the literature on dietary patterns and health outcomes, there are few studies that examine the nutrient content meal options offered to children at fast-food and sit-down restaurant chains, especially with respect to fiber and sodium content. Fiber and sodium have been the targets of recent public health campaigns. Fiber is a main constituent of fruits, vegetables, and whole grains and is associated with a lower risk of disease development, including diabetes, obesity, and coronary heart disease [7]. In

*Address correspondence to this author at the One Gustave L. Levy Place Box 1057, New York, NY 10029, USA; Tel: 212-824-7044; Fax: 212-996-0407;

E-mail: andrea.deierlein@mssm.edu contrast, sodium is added to the majority of processed foods and is linked to increased risk of hypertension and cardiovascular disease [8].

The main objective of this study was to describe and compare the average energy and nutrient profiles of meal options available on children's menus at popular sit-down and fast-food restaurant chains in the United States (US), focusing on calories, macronutrients, sodium, and fiber. We also compared these profiles to current dietary recommendations based on the 2010 Dietary Guidelines for Americans issued by the US Department of Agriculture and the US Department of Health and Human Services [9].

\section{METHODS}

The sample consisted of restaurants ranked within the top 50 restaurant chains in the US in 2009 [10]. Rankings were based on restaurants' total sales in 2008. The sample consisted of restaurants that offered entrees as part of meal options for children. Restaurants that offered only buffets, pizza, or convenience/snack options (ice cream, pastries, coffee, and other convenience items) were excluded $(n=11)$. Since the objective of this study was to describe the nutrient profiles of meal options on children's menus, restaurants that only provided one menu (presumably an adult menu) were excluded $(n=4)$. Lastly, restaurants that did not provide nutritional information 
for the meals (accessed June-July 2010) were excluded $(n=6)$. The remaining 29 restaurants were then classified as sit-down restaurants $(n=13)$ and fastfood restaurants $(n=16)$. Sit-down restaurants were defined as restaurants with wait-staff service and fastfood restaurants were defined as restaurants offering self-service or carry out without wait-staff service [11]. The total sample of 29 restaurants represented over $\$ 184$ billion in total sales for 2008 , with fast-food restaurants accounting for approximately $\$ 157$ billion of the sales $(85 \%)$.

In order to determine the average nutrient profiles of meals available to children at fast-food and sit-down restaurant chains, the nutrition information for all meals offered on the menus was calculated using all possible combinations of entrées and side options, including all size/portion options and all dressing/sauce options if provided. The following items were excluded from the analysis: meals that were not offered as part of restaurants' daily menus; meals on breakfast and lunch-specific menus; seasonal or region-specific offers; gluten-free or special diet meals; side salads or soups not labeled as a main "entrée" or not offered as part of a meal by the restaurant; desserts; additional sauces and toppings that were not specifically indicated for the meal; and unlimited meal offers, such as buffets. All beverages were also excluded.

\section{Statistical Analyses}

For children's menus, there were 421 possible meal combinations available at sit-down restaurants and 275 meal options available at fast-food restaurants. Nutrition information for all meal combinations was entered into an Excel database and Stata 11.0 was used for statistical analyses. Descriptive statistics were computed for total calories, fat $(\mathrm{g})$, percent calories from fat, total saturated fat $(\mathrm{g})$, percent calories from saturated fat, protein $(\mathrm{g})$, percent calories from protein, total carbohydrates $(\mathrm{g})$, percent calories from carbohydrates, fiber $(\mathrm{g})$, and sodium $(\mathrm{mg})$. The values for sodium represented sodium that was either naturally occurring in the food or was added during processing or preparation, not sodium from table salt added by the customer. Average nutrient information for children's meals was compared to recommendations provided by the 2010 Dietary Guidelines for Americans [9]. The percentages of calories from macronutrients within meals were calculated assuming 4 calories per gram of carbohydrates and protein and 9 calories per gram of fat and saturated fat. The percentage of calories from each macronutrient was compared to the recommended macronutrient ranges suggested in the Guidelines as follows: $45-65 \%$ carbohydrates; $10-30 \%$ protein; $25-35 \%$ fat; and less than $10 \%$ saturated fat [9]. The Guidelines' recommendations for sodium and fiber are age and gender-specific. For these analyses, we used reference daily intakes of $1500 \mathrm{mg}$ of sodium ( $1500 \mathrm{mg} /$ day is the Adequate Intake recommended for individuals ages 9 years and older and no more than $2200 \mathrm{mg} /$ day is recommended for children ages 9-13 years) and $25 \mathrm{~g}$ of fiber $(22 \mathrm{~g} /$ day and $25 \mathrm{~g} /$ day are recommended for girls and boys, respectively, ages 913 years).

\section{RESULTS}

In general, children's meal options at sit-down and fast-food restaurants exceeded the daily recommended intakes of fat, saturated fat, and sodium while they were within or below the recommendations for carbohydrates, protein, and fiber. The mean (standard deviation, SD), median, and ranges for: total calories (kcal), total fat $(\mathrm{g})$, percent of calories from fat $(\%)$, saturated fat $(\mathrm{g})$, percent of calories from saturated fat $(\%)$, protein $(\mathrm{g})$, percent of calories from protein (\%), carbohydrates $(\mathrm{g})$, percent of calories from carbohydrates $(\%)$, sodium $(\mathrm{mg})$, and fiber $(\mathrm{g})$ are shown in Table 1 for children's meal options at sit-down and fast-food restaurants. The frequencies (\%) of meal options at sit-down and fast-food restaurants that exceeded the 2010 Dietary Guidelines recommended daily intakes of percent of calories from fat, percent of calories from saturated fat, and sodium are displayed in Figure 1.

\section{Sit-Down Restaurants}

The average sit-down restaurant meal provided a mean energy intake of $537.7(S D=202.1)$ calories. Over one third of these calories were from fat with $12.1 \%$ $(S D=7.5)$ of calories from saturated fat. Children's meals contained a mean of $1118.9 \mathrm{mg}(\mathrm{SD}=587.2)$ of sodium, which is three quarters of the Adequate Intake (and over half the recommended limit of daily intake), and $4.6 \mathrm{~g}(\mathrm{SD}=2.7)$ of fiber, which is $18.4 \%$ of the recommended daily intake (Table 1 ). The majority of children's meal options from sit-down restaurants exceeded the recommended daily intakes of percent of calories from fat or saturated fat and one-fifth contained more than $1500 \mathrm{mg}$ of sodium (Figure 1). A total of $14.3 \%$ of children's meal options at sit-down restaurants exceeded the recommendations for all three of the selected nutrients. 
Table 1: Descriptive Nutrition Information for Meal Options on Adults' and Children's Menus at Sit-Down ( $\mathrm{n}=13$ ) and Fast-Food $(n=16)$ Chain Restaurants Ranked within the Top 50 Chain Restaurants in the United States

\begin{tabular}{|c|c|c|c|c|c|c|c|c|}
\hline & \multicolumn{4}{|c|}{ Sit-Down Restaurants $(n=13)$} & \multicolumn{4}{|c|}{ Fast-food Restaurants $(n=16)$} \\
\hline & $\mathbf{N}$ & Mean \pm SD & Median & Range & $\mathbf{N}$ & Mean \pm SD & Median & Range \\
\hline Children & 421 & & & & 275 & & & \\
\hline Calories (kcal) & 421 & $537.7 \pm 202.1$ & 510.0 & $125.0-1268.3$ & 275 & $529.5 \pm 162.7$ & 530.0 & $140.0-850.0$ \\
\hline Total Fat (g) & 421 & $24.8 \pm 15.4$ & 23.0 & $0.0-78.4$ & 275 & $23.2 \pm 9.1$ & 23.0 & $1.5-45.0$ \\
\hline $\begin{array}{c}\text { Percent Calories from } \\
\text { Fat }(\%)\end{array}$ & 421 & $38.3 \pm 15.1$ & 39.8 & $0.0-77.5$ & 275 & $38.7 \pm 8.4$ & 39.1 & $7.3-56.5$ \\
\hline Saturated Fat (g) & 296 & $8.4 \pm 7.0$ & 6.0 & $0.0-32.1$ & 275 & $9.2 \pm 5.1$ & 8.5 & $0.0-20.0$ \\
\hline $\begin{array}{l}\text { Percent Calories from } \\
\text { Saturated Fat (\%) }\end{array}$ & 296 & $12.1 \pm 7.5$ & 10.9 & $0.0-34.6$ & 275 & $15.1 \pm 6.3$ & 13.0 & $7.1-48.6$ \\
\hline Carbohydrates (g) & 408 & $55.0 \pm 24.9$ & 53.0 & $6.0-145.4$ & 275 & $60.1 \pm 20.5$ & 63.0 & $4.0-92.0$ \\
\hline $\begin{array}{l}\text { Percent Calories from } \\
\text { Carbohydrates }(\%)\end{array}$ & 408 & $42.0 \pm 15.9$ & 40.5 & $4.4-92.0$ & 275 & $45.3 \pm 8.7$ & 45.8 & $11.4-84.3$ \\
\hline Protein (g) & 316 & $24.2 \pm 9.4$ & 24.0 & $5.0-49.0$ & 275 & $18.3 \pm 4.5$ & 18.0 & $6.0-30.0$ \\
\hline $\begin{array}{l}\text { Percent Calories from } \\
\text { Protein (\%) }\end{array}$ & 316 & $19.3 \pm 10.9$ & 16.0 & $6.0-61.7$ & 275 & $15.1 \pm 6.3$ & 13.0 & $7.1-48.6$ \\
\hline Sodium (mg) & 421 & $1118.9 \pm 587.2$ & 1045.0 & $50.0-4398.0$ & 275 & $999.8 \pm 299.3$ & 997.0 & $270.0-1890.0$ \\
\hline Fiber (g) & 337 & $4.6 \pm 2.7$ & 4.0 & $0.0-14.8$ & 275 & $3.6 \pm 1.7$ & 3.0 & $0.0-12.0$ \\
\hline
\end{tabular}

\section{Fast-Food Restaurants}

The average fast-food restaurant children's meal provided a mean energy intake of $529.5(S D=162.7)$ calories. More than one third of these calories were from fat with $14.7 \% \quad(S D=5.5)$ from saturated fat. Children's meals contained a mean of $999.8 \mathrm{mg}$ $(S D=299.3)$ of sodium, which is two thirds of the Adequate Intake (and almost half the recommended limit of daily intake), and $3.6(S D=1.7) \mathrm{g}$ of fiber, which is $14.4 \%$ of the recommended intake (Table 1 ). Approximately $72 \%$ of children's meal options from fast-food restaurants exceeded the recommended daily intake of percent of calories from fat; $79 \%$ exceeded the recommended daily intake of percent of calories from saturated fat; and $3 \%$ of meals contained more than $1500 \mathrm{mg}$ of sodium (Figure 1).

\section{DISCUSSION}

The purpose of this study was to describe the average nutrient information of meal options available on children's menus at popular US sit-down and fastfood restaurant chains and to compare this information to the 2010 Dietary Guidelines for Americans [9]. The results show that meals offered at these restaurants, on average, accounted for large percentages of the recommended daily intakes of calories, fat, saturated fat, and sodium and small percentages of the recommended daily intakes of fiber, carbohydrates, and protein for children. More than half of children's meals at sit-down and fast-food restaurants exceeded the recommendations for fat and saturated fat.

Our study adds valuable information to the relatively sparse literature regarding the average nutrient profiles of meal options available to children at popular US restaurant chains. The average percent of calories from fat in children's meals ranged from approximately 38$50 \%$ and the average percent of calories from saturated fat ranged from approximately $12-16 \%$, exceeding national recommendations for children. Despite somewhat similar percent calorie distributions of macronutrients, children's meals at sit-down restaurants had higher average amounts of calories, fat, saturated fat, and sodium compared to meals at fast-food restaurants. These differences are likely due to larger portion sizes at sit-down restaurants compared to fast-food restaurants [12]. This finding is important because children consume larger quantities of energy-dense foods (such as those offered at fastfood and sit-down restaurants) as portion sizes increase and, consequently consume increased amounts of calories, fat, and other nutrients [13].

The average amounts of sodium in meals were particularly alarming, accounting for approximately half of the limited daily intake for children (based on a recommended intake of no more than $2200 \mathrm{mg} / \mathrm{day}$ ). 


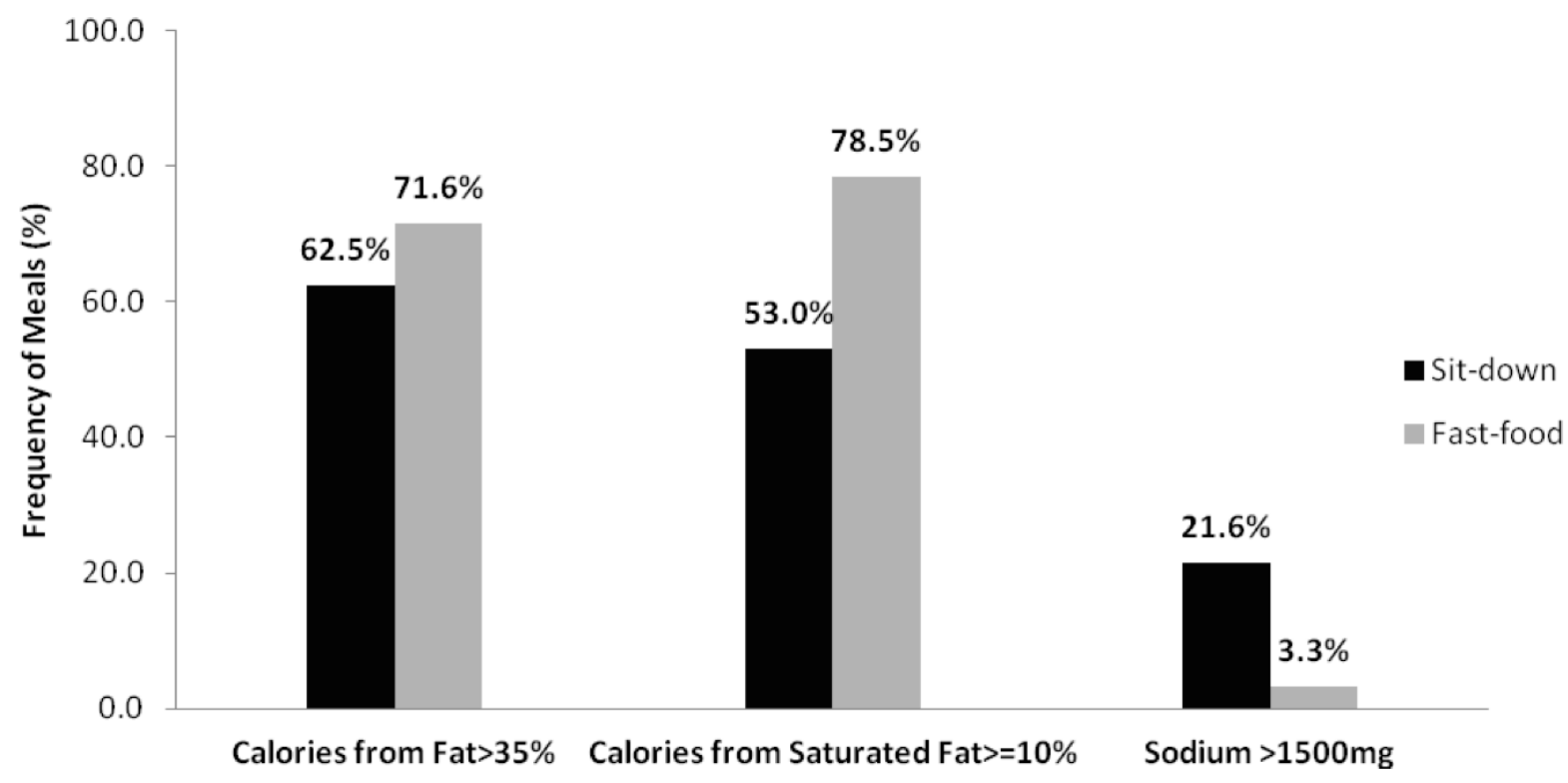

Figure 1: Frequency of children's meal options on menus at sit-down and fast-food chain restaurants that exceeded the 2010 Dietary Guidelines recommendations for daily intakes of percent of calories from fat, percent of calories from saturated fat, and sodium $^{\mathrm{a}}$.

${ }^{a}$ Among sit-down restaurants $(n=13)$, there were 421 meals with available nutrition information for calories from fat; 296 meals for calories from saturated fat; and 421 meals for sodium. Among fast-food restaurants $(n=16)$, there were 275 meals with available nutrition information for calories from fat, calories from saturated fat, and sodium.

Excess dietary sodium contributes to the later development of hypertension, which is a known risk factor for adverse cardiovascular events and kidney disease [14,15]. Reductions in dietary sodium are associated with decreased systolic and diastolic blood pressure in children [16]. In contrast to sodium, the average amounts of fiber in meals were low, providing less than one fifth of the recommended intake for children. In adults, dietary fiber is positively associated with satiety and acts to decrease hunger, thereby playing an important role in body weight regulation and the prevention of obesity, as well as the related comorbidites, such as diabetes [17-19]. Though evidence for such health benefits of dietary fiber among children is currently not established, it is likely that fiber plays an important role in children's health [17].

Previous studies have described the nutrient profiles of fast-food and/or chain restaurant meal options, using varying methodologies, and the results are consistent with and complement the results of the current study $[20,21]$. Higher intakes of calories, fat, and added sugars are reported when children consume foods at fast-food and other restaurants [3,12,22,23]. In a cross-sectional study of participants in the Continuing Survey of Food Intakes by Individuals (1994-1998), fast-food use was reported by $42 \%$ of children. Children with reported fast-food consumption on a given day had higher calorie, fat, saturated fat, sodium, and soft drink intakes and lower vitamin, fruit, vegetable, and milk intakes compared to a day when fast-food was not consumed and compared to nonconsumers of fast-food [24]. Only $3 \%$ of fast-food kids' meals offered at major fast-food restaurant chains met all of the criteria of the National School Lunch Program [23]. In a comparison of children's meals at fast-food and non-fast-food restaurants, the overall mean percentages of calories from fat were similar $(37.5 \%$ at fast-food vs. $40.5 \%$ at non-fast-food restaurants) and there were no significant differences in macronutrient content when evaluating meals with the highest calorie side item at the two types of restaurants [12]. However, similar to the findings in the current study, children's meals at fast-food restaurants were smaller, contained less calories, fat, saturated fat, protein, carbohydrates, and fiber, and included lower calorie side options compared to meals at non-fast-food restaurants [12].

The results of this study should be considered within the context of its limitations. This is a descriptive study reporting the average nutrient profiles of children's meal options from menus posted on restaurants' websites in 2010; therefore, we cannot comment on recent menu changes, regional differences in meal options, or consumer purchasing behaviors of meals. We used nutrition information that was provided by restaurants rather than an independent source. Previous studies suggest that 
some of this nutrient information may be underreported [25], which would likely underestimate the reported average meal nutrient values. Also, by design of our study, we were unable to account for any condiments, sauces, or salt added (or subtracted) during or after food preparation and any beverages consumed with the meals. Such additions to meals would likely account for substantial increases in calories, macronutrients, and sodium. Overall, these limitations suggest that the reported nutrient content of meals is lower than what is actually being consumed by children.

\section{CONCLUSIONS}

Sit-down and fast-food chain restaurants offer convenient, affordable, and quick meal options for children [26]; however, evidence from this study and others $[3,12,20-23]$ show that the majority of these meals are high in calories, fat, and sodium and low in fiber. Meals at sit-down chain restaurants may be of particular concern because of large portion sizes. Public health initiatives to increase consumer knowledge and awareness by providing nutrition information on menus in chain restaurants may help guide consumers to make healthier choices [27,28], especially for children [29], but are likely inadequate to prevent excessive dietary intakes $[28,30]$. Alterations to restaurant meals that favor low calorie options, reduce portion sizes [31], and include fruits, vegetables, and whole grains are necessary to decrease calories, fat, and sodium and increase fiber intakes among child consumers.

\section{COMPETING INTERESTS}

The authors declare that they have no competing interests. All authors were involved in the implementation of the study as well as read and approved the final manuscript.

\section{ACKNOWLEDGEMENTS}

This work was supported by the Research Training Program in Environmental Pediatrics (T32HD049311) and the Short-term Training Programs for Minority Students (R25 HL108857 and T35 ES007298). The authors would like to thank Brenda Vazquez for her assistance in gathering restaurant information and participating in data entry.

\section{REFERENCES}

[1] Guthrie JF, Lin BH, Frazao E. Role of food prepared away from home in the American diet, 1977-78 versus 1994-96: changes and consequences. J Nutr Educ Behav 2002; 34: 140-50.

http://dx.doi.org/10.1016/S1499-4046(06)60083-3

[2] Ayala GX, Rogers M, Arredondo EM, et al. Away-from-home food intake and risk for obesity: Examining the influence of context. Obesity 2008; 16: 1002-8.

http://dx.doi.org/10.1038/oby.2008.34

[3] Bowman SA, Gortmaker SL, Ebbeling CB, Pereira MA, Ludwig DS. Effects of fast-food consumption on energy intake and diet quality among children in a national household survey. Pediatrics 2004; 113: 112-8.

http://dx.doi.org/10.1542/peds.113.1.112

[4] French SA, Story M, Neumark-Sztainer D, Fulkerson JA, Hannan P. Fast food restaurant use among adolescents: associations with nutrient intake, food choices and behavioral and psychosocial variables. Int J Obes 2001; 25: 1823-33. http://dx.doi.org/10.1038/sj.ijo.0801820

[5] Duffey KJ, Gordon-Larsen P, Jacobs DR, Williams OD, Popkin BM. Differential associations of fast food and restaurant food consumption with 3-y change in body mass index: the Coronary Artery Risk Development in Young Adults Study. Am J Clin Nutr 2007; 85: 201-8.

[6] Duffey KJ, Gordon-Larsen P, Steffen LM, Jacobs DR, Popkin BM. Regular consumption from fast food establishments relative to other restaurants is differentially associated with metabolic outcomes in young adults. J Nutr 2009; 139: 21138.

http://dx.doi.org/10.3945/jn.109.109520

[7] Anderson JW, Baird P, Davis $\mathrm{RH}$, et al. Health benefits of dietary fiber. Nutr Rev 2009; 67: 188-205. http://dx.doi.org/10.1111/j.1753-4887.2009.00189.x

[8] Frieden TR, Briss PA. We can reduce dietary sodium, save money, and save lives. Ann Int Med 2010; 152: 526-7. http://dx.doi.org/10.7326/0003-4819-152-8-20100420000214

[9] U.S. Department of Agriculture and U.S. Department of Health and Human Services. Dietary Guidelines for Americans, $20107^{\text {th }}$ ed. Washington, DC: U.S. Government Printing Office; December 2010.

[10] Restaurants \& Institutions. R\&I 2009 Top 400 Restaurant Chains. Accessed 06/01, 2010. Reference available from: http://www.rolypoly.com/news/articles/R\&I2009Top400 RestaurantChains.pdf.

[11] Biing-Hwan L, Frazao E. Nutritional quality of foods at and away from home. Food Review. US Government Printing Office, Food and Rural Economics Division, Economics Research Service, USDA 1997; pp. 499-503.

[12] Serrano EL, Jedda VB. Comparison of fast-food and nonfast-food children's menu items. J Nutr Educ Behav 2009; 41 : 132-7. http://dx.doi.org/10.1016/i.jneb.2008.02.005

[13] Fisher JO, Kral TVE. Super-size me: Portion size effects on young children's eating. Phys Behav 2008; 94: 39-47. http://dx.doi.org/10.1016/j.physbeh.2007.11.015

[14] Jones DW. Dietary sodium and blood pressure. Hypertension 2004; 43: 932-5 http://dx.doi.org/10.1161/01.HYP.0000126610.89002.c6

[15] MacGregor GA. Salt: blood pressure, the kidney, and other harmful effects. Nephrol Dial Transplant 1998; 13: 2471-9. http://dx.doi.org/10.1093/ndt/13.10.2471

[16] Aburto NJ, Ziolkovska A, Hooper L, Elliott P, Cappuccio FP Meerpohl JJ. Effect of lower sodium intake on health: systematic review and meta-analysis. BMJ 2013; 346: 1326. http://dx.doi.org/10.1136/bmj.f1326

[17] Kranz S, Brauchla M, Slavin JL, Miller KB. What do we know about dietary fiber intake in children and health? The effects of fiber intake on constipation, obesity, and diabetes in children. Adv Nutr 2012; 3: 47-53. http://dx.doi.org/10.3945/an.111.001362 
[18] Pereira MA, Ludwig DS. Dietary fiber and body-weight regulation. Observations and Mechanisms. Pediatr Clin Nor Am 2001; 48: 969-80. http://dx.doi.org/10.1016/S0031-3955(05)70351-5

[19] Howarth NC, Saltzman E, Roberts SB. Dietary fiber and weight regulation. Nutr Rev 2001; 59: 129-39. http://dx.doi.org/10.1111/j.1753-4887.2001.tb07001.x

[20] Batada A, Bruening M, Marchlewicz EH, Story M, Wootan MG. Poor nutrition on the menu: children's meals at America's top chain restaurants. Child Obes 2012; 8: 251-4. http://dx.doi.org/10.1089/chi.2012.0016

[21] Wu HW, Sturm R. What's on the menu? A review of the energy and nutritional content of US chain restaurant menus. Public Health Nutr 2013; 16: 87-96. http://dx.doi.org/10.1017/S136898001200122X

[22] Zoumas-Morse C, Rock CL, Sobo EJ, Neuhouser ML. Children's patterns of macronutrient intake and associations with restaurant and home eating. J Am Diet Assoc 2001; 101: 923-5.

http://dx.doi.org/10.1016/S0002-8223(01)00228-0

[23] O'Donnell SI, Hoerr SL, Mendoza JA, Goh ET. Nutrient quality of fast food kids meals. Am J Clin Nutr 2008; 88: 1388-95.

[24] Paeratakul S, Ferdinand DP, Champagne CM, Ryan DH, Bray GA. Fast-food consumption among US adults and children: dietary and nutrient intake profile. J Am Diet Assoc 2003; 103: 1332-8. http://dx.doi.org/10.1016/S0002-8223(03)01086-1

[25] Urban LE, McCrory MA, Dallal GE, Das SK, Saltzman E, Weber JL, et al. Accuracy of stated energy contents of restaurant foods. JAMA 2011; 306: 287-93. http://dx.doi.org/10.1001/jama.2011.993
[26] Rydell SA, Harnack LJ, Oakes JM, Story M, Jeffrey RW, French SA. Why eat at fast-food restaurants: reported reasons among frequent consumers. J Am Diet Assoc 2008; 108: 2066-70.

http://dx.doi.org/10.1016/j.jada.2008.09.008

[27] Elbel B. Consumer estimation of recommended and actual calories at fast food restaurants. Obesity 2011; 19: 1971-8. http://dx.doi.org/10.1038/oby.2011.214

[28] Dumanovsky T, Huang CY, Nonas CA, Matte T, Bassett MT Silver LD. Changes in energy content of lunchtime purchases from fast food restaurants after introduction of calorie labeling: cross sectional customer surveys. BMJ 2011; 343: d4464.

http://dx.doi.org/10.1136/bmj.d4464

[29] Tandon PS, Wright J, Zhou C, Rogers CB, Christakis DA. Nutrition menu labeling may lead to lower-calorie restaurant meal choices for children. Pediatrics 2010; 125: 244-8. http://dx.doi.org/10.1542/peds.2009-1117

[30] Girz L, Polivy J, Herman CP, Lee H. The effects of calorie information on food selection and intake. Int $\mathrm{J}$ Obes 2012; 36: $1340-5$

http://dx.doi.org/10.1038/ijo.2011.135

[31] Dumanovsky T, Nonas CA, Huang CY, Silver LD, Bassett MT. What people buy from fast-food restaurants: caloric content and menu item selection, New York City 2007. Obesity 2009; 17: 1369-1374.

http://dx.doi.org/10.1038/oby.2009.90

Received on 21-02-2014

Accepted on 24-04-2014

Published on 30-05-2014

http://dx.doi.org/10.6000/1929-4247.2014.03.02.6

(C) 2014 Deierlein et al.; Licensee Lifescience Global.

This is an open access article licensed under the terms of the Creative Commons Attribution Non-Commercial License (http://creativecommons.org/licenses/by-nc/3.0/) which permits unrestricted, non-commercial use, distribution and reproduction in any medium, provided the work is properly cited. 